\title{
PENGEMBANGAN MEDIA PEMBELAJARAN SCRAPBOOK MATERI KARANGAN DESKRIPSI MATA PELAJARAN BAHASA INDONESIA KELAS III SEKOLAH DASAR
}

\author{
Tiara Kusnia Dewi, dan Rina Yuliana \\ PGSD FKIP Universitas Sultan Ageng Tirtayasa \\ Email: rinayuliana@untirta.ac.id
}

\section{Info Artikel}

\section{Sejarah Artikel:}

Diterima 3 Oktober 2018

Direvisi 7 November 2018

Disetujui 28 November 2018

\section{Keywords:}

Scrapbook media, Indonesian Language, 3rd grade of elementary school

\begin{abstract}
This study aims to find out how to develop scrapbook learning media for the material essay description on the subjects of Indonesian in grade III primary school and to determine the feasibility of scrapbook learning media for the material essay description on the Indonesian language in grade III developed elementary school received a judgment worthy of experts. This research was conducted in SDN Banjar Agung 4 with the subjects of class III-A students of 28 students with the details of 17 students on a limited trial. The type of research used refers to the development model Thiagarajan, Semmel, and Semmel. This model consists of 3 stages namely, defining (define), planning (design), development stage (develop). The instruments used are questionnaires for media validation by expert lecturers as well as teacher and student response questionnaire. Based on data analysis, it can be concluded that the quality of scrapbook media developed is included in very decent category with $96.11 \%$ percentage from 2 material experts, very decent category with $85 \%$ percentage from 2 media experts, and 94\% from 2 linguists. Student response to media scrapbook on trial with 17 respondents equal to $89,83 \%$ with very good category.
\end{abstract}

\begin{abstract}
Abstrak
Penelitian ini bertujuan untuk mengetahui cara mengembangkan media pembelajaran scrapbook untuk materi karangan deskripsi pada mata pelajaran bahasa Indonesia pada kelas III sekolah dasar dan untuk mengetahui kelayakan media pembelajaran scrapbook untuk materi karangan deskripsi pada mata pelajaran bahasa Indonesia pada kelas III sekolah dasar yang dikembangkan mendapat penilaian yang layak dari pakar. Penelitian ini dilakukan di SDN Banjar Agung 4 dengan subjek penelitian siswa kelas III-A sejumlah 28 siswa dengan rincian 17 siswa pada uji coba terbatas. Jenis penelitian yang digunakan mengacu pada model pengembangan Thiagarajan, Semmel, dan Semmel. Model ini terdiri atas 3 tahap yakni, tahap pendefinisian (define), tahap perencanaan (design), tahap pengembangan (develop). Instrumen yang digunakan berupa lembar angket untuk validasi media oleh dosen ahli serta guru dan lembar angket respon siswa. Berdasarkan analisis data dapat disimpulkan kualitas media scrapbook yang dikembangkan termasuk dalam kategori sangat layak dengan presentase $96,11 \%$ dari 2 ahli materi, kategori sangat layak dengan presentase $85 \%$ dari 2 ahli media, dan $94 \%$ dari 2 ahli bahasa. Respon siswa terhadap media scrapbook pada uji coba dengan 17 responden sebesar $89,83 \%$ dengan kategori sangat baik.
\end{abstract}

(C) 2018 Universitas Muria Kudus 
Dewi, Tiara Kusnia., dan Yuliana, Rina

PENGEMBANGAN MEDIA PEMBELAJARAN SCRAPBOOK ...

REFLEKSI EDUKATIKA : Jurnal Ilmiah Kependidikan, Nomor 9, Volume 1, Desember 2018, hlm. 19-25

\section{PENDAHULUAN}

Keterampilan menulis merupakan keterampilan yang harus dikembangkan secara dini mulai dari pendidikan dasar dengan cara yang metodis dan sistematis. Tanpa pembinaan secara metodis dan sistematis, sulit keterampilan ini dimiliki. Keterampilan menulis pada pembelajaran bahasa indonesia di sekolah dasar merupakan aspek yang harus ditekankan dalam pembinaannya, disamping keterampilan membaca dan berhitung. Hal demikian agar siswa mampu berkomunikasi baik secara lisan maupun tulisan. Kemampuan menulis secara efektif sangat diperlukan para peserta didik, tidak hanya sebagai sarana belajar di sekolah, tetapi keterampilan berbahasa ini sangat penting dalam menunjang aktivitas kehidupan sehari-hari dan pada masa memasuki dunia kerja.

Suparno dan Yunus dalam Triambodo (2015: 2) menjelaskan menulis adalah sebagai suatu kegiatan penyampaian pesan (komunikasi) dengan menggunakan bahasa tulis sebagai alat atau medianya. Menulis juga diartikan sebagai proses penyampaian pikiran, angan-angan, perasaan dalam bentuk lambang atau tanda atau tulisan yang bermakna (Dalman dalam Sari, 2014:2). Menulis merupakan kegiatan yang dilakukan seseorang untuk menghasilkan sebuah tulisan. Oleh sebab itu menulis lebih dipahami sebagai keterampilan, bukan sebagai ilmu (Widiarto dalam Perdanita 2017: 2).

Kegiatan menulis merupakan sesuatu yang harus dilatih, dibiasakan, dan dilakukan oleh seseorang sejak dini, agar menulis menjadi sebuah keterampilan yang mahir yang dimiliki dan dikuasai oleh seseorang. Sayangnya, dalam pembelajaran menulis masih menyisakan sejumlah masalah serius. Salah satu masalah serius tersebut yakni rendahnya kemampuan siswa dalam menulis (Abidin 2015: 190-192). Hal tersebut senada dengan hasil penelitian yang dilakukan oleh Kasmaboti (2016: 96) yang menyatakan bahwa penyebab dari masalah rendahnya kemampuan siswa dalam menulis khususnya pada materi karangan adalah kurangnya menerapkan langkah-langkah dalam mengarang. Guru hanya memberikan tema karangan kemudian siswa ditugaskan membuat karangan dengan tema yang telah ditentukan tanpa mengawasi selama proses pembuatan karangan tersebut.

Proses pembelajaran pada jenjang pendidikan sekolah dasar, masih sangat jauh dari yang diharapkan. Secara realitas pada jenjang pendidikan sekolah dasar, khususnya pada pembelajaran bahasa Indonesia memiliki kecenderungan para guru masih terpaku pada pendekatan verbal dengan metode ceramah tanpa menggunakan media dalam mengkomunikasikan materi pelajaran pada siswa, sehingga berdampak pada proses pembelajaran yang monoton dan membosankan siswa. Padahal jika melihat usia anak sekolah dasar yang rata-rata berkisar 6 sampai dengan 13 tahun yang dihubungkan dengan teori Piaget, anak sekolah dasar tergolong dalam fase (tingkat) operasional kongkrit yang artinya dalam fase ini anak atau siswa betul-betul pada masa yang sangat nyata atau kongkrit, dan belum dapat memahami halhal yang abstrak. Hal ini senada dengan pernyataan Yuliana dkk dalam Fathurohman (2014: 2) bahwa karakteristik anak usia SD masih berada pada tahap operasional kongrit dan anak memiliki kemampuan pada aspek kognitif, afektif, dan psikomotor. Oleh karena itu, dibutuhkan adanya sebuah media pembelajaran untuk membuat sesuatu yang abstrak menjadi nyata dan memudahkan siswa memahami apa yang sebelumnya tidak diketahuinya.

Media pembelajaran merupakan sebuah alat yang berfungsi dan digunakan untuk memudahkan proses pembelajaran. Pembelajaran merupakan proses komunikasi antara pembelajar, pengajar, dan bahan ajar. Media ini menjadi komponen sumber belajar atau wahana fisik yang mengandung materi instruksional bagi peserta didik yang dapat merangsang peserta didik untuk belajar. Salah satu media alternatif sebagai solusi atas beberapa masalah yang telah peneliti paparkan di atas yakni media scrapbook untuk materi karangan deskipsi pada pembelajaran bahasa Indonesia.

Hamidjojo dalam Hosnan (2015: 111) juga menyatakan bahwa media pembelajaran adalah media yang penggunaanya diintegrasikan dengan tujuan dan isi pelajaran yang bermaksud untuk mempertinggi kegiatan belajar mengajar dalam segi mutu. Sehubungan dengan itu, Sudjana dan Rivai dalam Arsyad (2011: 23) mengemukakan manfaat media pembelajaran dalam proses belajar siswa, sebagai berikut 1) Pembelajaran akan lebih menarik perhatian siswa, 2) Bahan pembelajaran akan lebih jelas maknanya hingga dapat lebih dipahami, 3) Metode mengajar akan lebih bervariasi, 4) Siswa dapat lebih banyak melakukan kegiatan belajar.

Sehubungan dengan penelitian sebelumnya yang menyatakan bahwa, media scrapbook adalah media berupa tempelan gambar atau hiasan lain yang diaplikasikan di 
Dewi, Tiara Kusnia., dan Yuliana, Rina

PENGEMBANGAN MEDIA PEMBELAJARAN SCRAPBOOK ...

REFLEKSI EDUKATIKA : Jurnal Ilmiah Kependidikan, Nomor 9, Volume 1, Desember 2018, hlm. 19-25

atas kertas (Sprachforum dalam Heryaneu, Amir dan Pepen 2015: 4). Scrapbook merupakan seni menempel foto di media kertas dan menghiasinya menjadi karya kreatif. Menurut Kompas.com (2013) dalam Heryaneu, Amir dan Pepen (2015: 4) menyatakan bahwa scrapbook memiliki beberapa manfaat, diantaranya: membuat peserta didik menjadi lebih kreatif, menyalurkan hobi, dokumentasi, dan sarana untuk rekreasi dan penghilang stress.

Adapun kelebihan dari media scrapbook, yaitu scrapbook mencerminkan keunikan dari pemikiran, hidup, dan aktivitas penulisnya, sifatnya kongkrit dan lebih realistis menunjukan pokok permasalahan yang dibahas, scrapbook dapat mengatasi ruang dan waktu, scrapbook dapat mengatasi keterbatasan pengamatan kita, dan bahan-bahan membuat scrapbook mudah didapat, tanpa menggunakan peralatan khusus. Kemudian, terdapat ciri khas dari media pembelajaran scrapbook yang akan dikembangkan ini yaitu bertemakan lingkungan dan sesuai dengan konteks siswa. Jadi, siswa akan dilatih untuk belajar menulis karangan deskripsi dan mengenal nama-nama tempat yang berada di sekitar siswa (lingkungan siswa).

Berdasarkan hal tersebut, peneliti melakukan kajian dan pembahasan mengingat keberadaan scrapbook terbilang cukup dibutuhkan dalam proses pembelajaran sebagai salah satu media pembelajaran. Penggunaan media scrapbook bisa digunakan sebagai salah satu alternatif untuk melatih keterampilan menulis siswa pada mata pelajaran bahasa Indonesia dan diharapkan penggunaan media pembelajaran scrapbook ini dapat menambah motivasi peserta didik dalam belajar bahasa Indonesia khususnya pada kegiatan pembelajaran menulis.

Berdasarkan batasan masalah di atas, maka penelitian ini bertujuan untuk mengetahui cara mengembangkan media pembelajaran scrapbook untuk materi karangan deskripsi pada mata pelajaran bahasa Indonesia di kelas III sekolah dasar dan untuk mengetahui kelayakan media pembelajaran scrapbook untuk materi karangan deskripsi pada mata pelajaran bahasa Indonesia di kelas III sekolah dasar yang dikembangkan mendapat penilaian yang layak dari pakar.

Scrapbook ini digunakan pada materi karangan deskripsi yakni pada mata pelajaran bahasa Indonesia kelas III SD. Media ini terbuat dari tempelan-tempelan kertas artcartoon dengan tampilan 2D dan 3D disertai kantong-kantong kata. Bentuk media ini berupa buku yang berisi gambar dan teks berkaitan karangan deskripsi. Adapun ciri khas dari media pembelajaran scrapbook ini yakni konten atau isi dari scrapbook sesuai dengan konteks siswa, peserta didik diharapkan dapat berlatih menulis khususnya berlatih mendeskripsikan sesuatu sekaligus mengenal tempat-tempat yang berada di lingkungan sekitar siswa.

Media pembelajaran memiliki manfaat dalam kegiatan belajar mengajar di sekolah, bahasa Indonesia sangat penting dipelajari anakanak sekolah dasar. Bahasa Indonesia sebagai sarana berkomunikasi, untuk saling berbagi pengalaman, saling belajar dari yang lain, serta untuk meningkatkan kemampuan intelektual dan kesusastraan Indonesia. Adapun harapan pelajaran bahasa Indonesia agar para siswa mampu mengembangkan pengetahuan, keterampilan berbahasa, dan bersikap positif terhadap bahasa Indonesia, serta menghargai manusia dan nilai-nilai kemanusiaan. Hal tersebut senada dengan yang diutarakan oleh Jamaluddin dalam Puspidalia (2012: 3), tujuan umum pembelajaran bahasa dan sastra Indonesia lebih bersifat filosofis, sedangkan tujuan khususnya bersifat operasional.

Ada lima tujuan umum yang telah dirumuskan dalam kurikulum, yakni (1) siswa menghargai dan membanggakan bahasa Indonesia sebagai bahasa nasional dan bahasa negara; (2) siswa memahami bahasa Indonesia dari segi bentuk, makna dan fungsi, serta menggunakannya dengan tepat dan kreatif untuk brmacam-macam tujuan, keperluan, dam keadaan; (3) siswa memiliki kemampuan menggunakan bahasa Indonesia untuk meningkatkan kemampuan intelektual, kematangan emosional, dan kematangan sosial; (4) siswa memiliki disiplin dalam berpikir dan berbahasa (berbicara dan menulis); dan (5) siswa mampu menikmati dan memanfaatkannya karya sastra untuk mengembangkan kepribadian, memperluas wawasan kehidupan, serta meningkatkan pengetahuan dan kemampuan berbahasa.

Berdasarkan uraian pada pendahuluan, peneliti melakukan pengembangan terhadap media pembelajaran yang harapannya dapat digunakan dan bermanfaat pada mata pelajaran bahasa Indonesia khususnya untuk materi karangan deskripsi di kelas III sekolah dasar yaitu scrapbook. Senada dengan hal itu, Wanabuliandari dalam Anugraheni (2018: 133) menyatakan bahwa konsep pembelajaran dapat 
Dewi, Tiara Kusnia., dan Yuliana, Rina

PENGEMBANGAN MEDIA PEMBELAJARAN SCRAPBOOK ...

REFLEKSI EDUKATIKA : Jurnal Ilmiah Kependidikan, Nomor 9, Volume 1, Desember 2018, hlm. 19-25

dilaksanakan bila informasi tersebut menarik dan memotivasi siswa untuk terus belajar. Oleh karena itu, sebelum melakukan kegiatan pembelajaran di kelas, guru harus mampu menumbuhkan aktivitas siswa. Dalam pelaksanaan pembelajaran diasumsikan setiap peserta didik memiliki perilaku yang mampu berkembang berdasarkan potensi alami dan sentuhan emosional artistik oleh guru (Sunarto 2018: 110)

\section{METODE PENELITIAN}

Metode penelitian yang digunakan yakni metode penelitian dan pengembangan atau Research and Development ( $R \& D$ ) yaitu metode penelitian yang digunakan untuk menghasilkan produk tertentu dan menguji keefektifan produk tersebut supaya dapat berfungsi di masyarakat luas (Sugiyono 2010: 407). Subjek penelitian yang digunakan, penelitian ini adalah SDN Banjar Agung 4 kelas 3 sebagai populasi penelitian. Adapun subjek penelitian yang peneliti jadikan sebagai sampel, yakni Kelas IIIA SDN Banjar Agung 4.

Penelitian berfokus pada pengembangan media pembelajaran scrapbook pada materi khususnya karangan deskripsi. Penelitian ini menggunakan model 3-D yang terdiri atas tiga tahapan. Pertama, tahap define yang terdiri atas kegiatan analisis kurikulum, analisis kebutuhan, analisis materi. Kedua, tahap design yang terdiri atas mendesain media dan dilanjutkan pembuatan media scrapbook. Ketiga, tahap develop yang terdiri atas validasi ahli (ahli media, ahli materi, dan ahli bahasa), revisi produk, dan uji coba terbatas. Penelitian ini terbatas hanya sampai revisi produk tahap akhir. Penelitian ini dilakukan pengumpulan data melalui instrumen ahli dan angket respon siswa.

Teknik pengolahan data dilakukan dengan mengolah data primer pada angket yang telah diisi oleh setiap validator media pembelajaran dan siswa di SDN Banjar Agung 4 dengan cara menghitung skor di setiap aspek dan indikator pada angket penilaian media pembelajaran dan angket respon siswa, kemudian data dianalisis antara indikator satu dengan indikator lainnya selanjutnya ditarik simpulan mengenai kelayakan media pembelajaran scrapbook untuk digunakan dalam materi karangan deskripsi pada mata pelajaran bahasa Indonesia di kelas III sekolah dasar.

\section{HASIL DAN PEMBAHASAN}

Penelitian serta pengembangan media pembelajaran scrapbook untuk materi karangan deskripsi pada mata pelajaran bahasa Indonesia dilakukan melalui observasi, penyebaran angket, dokumentasi, serta wawancara wali kelas III-A dan siswa di SDN Banjar Agung 4. Sebelum melaksanakan praktik mengajar (pelaksanaan penelitian di kelas). Peneliti melakukan kegiatan pra penelitian dengan melakukan identifikasi masalah yang diperoleh melalui hasil penelitian sebelumnya, yakni pada penelitian yang dilakukan oleh Yukeu Heryaneu, Amir, Pepen pada tahun (2015) dan hasil observasi peneliti mengenai pembelajaran menulis di SD Negeri Banjar Agung 4. Setelah melakukan pra penelitian, peneliti membuat media scrapbook untuk materi karangan deskripsinya.

Tahap Pembuatan Media Scrapbook, sebagai berikut 1) Pada tahap awal pembuatan media scrapbook yakni pembuatan storyboard atau rancangan awal media yang akan dibuat, 2) Pengumpulan gambar yang dibutuhkan dalam pembuatan media scrapbook sesuai dengan materi karangan sederhana (karangan deskripsi), 3) Pengeditan gambar, lalu gambar di edit menggunakan aplikasi Ms. Word, pengeditan gambar dilakukan agar komposisi gambar dapat sesuai dengan kebutuhan materi, contohnya memotong gambar-gambar untuk memberikan efek timbul pada gambar, 4) Mencetak gambar, gambar di cetak pada kertas A3+ dengan jenis kertas art cartoon $210 \mathrm{~g}$. Pemilihan kertas berdasarkan kualitas kertas yang baik dan lebih mudah untuk dibuat scrapbook.

Setelah media selesai dibuat, langkah selanjutnya memvalidasi media scrapbook kepada 3 ahli, yakni ahli materi, ahli media, dan ahli bahasa. Ahli materi berperan untuk memberikan penilaian terhadap media adalah guru atau wali kelas III SD Negeri Banjar Agung 4. Guru yang dilibatkan sebagai ahli materi berperan untuk memberikan penilaian terhadap media dari segi isi materi dan kegiatan pembelajaran. Guru yang menjadi ahli materi adalah Wali Kelas III-A SD Negeri Banjar Agung 4 yakni Ibu Yaroh Sumastuti, S.Pd. Wali Kelas III-B SD Negeri Banjar Agung 4, yakni Bapak Marhali, S.Pd. 
Dewi, Tiara Kusnia., dan Yuliana, Rina

PENGEMBANGAN MEDIA PEMBELAJARAN SCRAPBOOK ...

REFLEKSI EDUKATIKA : Jurnal Ilmiah Kependidikan, Nomor 9, Volume 1, Desember 2018, hlm. 19-25

Tabel 1. Data Penilaian Validasi Ahli Materi

\begin{tabular}{|c|c|c|c|c|}
\hline No. & $\begin{array}{c}\text { Aspek } \\
\text { Penilaian }\end{array}$ & $\begin{array}{c}\text { Ahli } \\
\text { Materi } \\
\text { I }\end{array}$ & $\begin{array}{c}\text { Ahli } \\
\text { Materi } \\
\text { II }\end{array}$ & $\begin{array}{c}\text { Skor } \\
\text { Rata- } \\
\text { rata }\end{array}$ \\
\hline 1. & $\begin{array}{c}\text { Kelayakan } \\
\text { Isi }\end{array}$ & 60 & 55 & 57,5 \\
\hline 2. & $\begin{array}{c}\text { Kelayakan } \\
\text { Penyajian }\end{array}$ & 30 & 28 & 29 \\
\hline \multicolumn{2}{|c|}{ Jumlah } & 90 & 83 & $\mathbf{8 6 , 5}$ \\
\hline \multicolumn{2}{|c|}{ Rerata Skor } & 5 & 4,61 & $\mathbf{4 , 8 0}$ \\
\hline \multicolumn{2}{|c|}{ Presentase Nilai } & $100 \%$ & $92,2 \%$ & $\mathbf{9 6 , 1 1} \%$ \\
\hline
\end{tabular}

Berdasarkan tabel kriteria analisis data penilaian validasi ahli materi didapatkan presentase nilai akhir sebesar 96,11 \% masuk pada kriteria "Sangat Layak". Sehubungan dengan itu, dosen ahli media yang berperan untuk memberikan penilaian terhadap media dari segi teknis dan penggunaan media dalam pembelajaran.

Dosen yang menjadi ahli media, yakni Bapak Aan Subhan Pamungkas, M.Pd selaku dosen mata kuliah Dasar Teknologi dan Informasi Pendidikan pada Jurusan Pendidikan Guru Sekolah Dasar dan Ibu Isna Rafianti, M.Pd selaku dosen mata kuliah Psikologi Pengambangan Bahan Ajar pada jurusan Pendidikan Matematika yang juga berpengalaman dalam bidang scrapbook. Kedua dosen tersebut adalah dosen pada Universitas Sultan Ageng Tirtayasa.

Tabel 2. Data Penilaian Validasi Ahli Media

\begin{tabular}{|c|c|c|c|c|}
\hline No. & $\begin{array}{c}\text { Aspek } \\
\text { Penilaian }\end{array}$ & $\begin{array}{c}\text { Ahli } \\
\text { Media } \\
\text { I }\end{array}$ & $\begin{array}{c}\text { Ahli } \\
\text { Media } \\
\text { II }\end{array}$ & $\begin{array}{c}\text { Skor } \\
\text { Rata- } \\
\text { rata }\end{array}$ \\
\hline 1. & $\begin{array}{c}\text { Komunikasi } \\
\text { Visual }\end{array}$ & 62 & 63 & 62,5 \\
\hline 2. & $\begin{array}{c}\text { Rekayasa } \\
\text { Media }\end{array}$ & 35 & 27 & 31 \\
\hline \multicolumn{2}{|c|}{ Jumlah } & 97 & 90 & $\mathbf{9 3 , 5}$ \\
\hline \multicolumn{2}{|c|}{ Rerata Skor } & 4,4 & 4,09 & $\mathbf{4 , 2 5}$ \\
\hline \multicolumn{2}{|c|}{ Presentase Nilai } & $\begin{array}{c}88,18 \\
\%\end{array}$ & $\begin{array}{c}81,81 \\
\%\end{array}$ & $\mathbf{8 5} \%$ \\
\hline
\end{tabular}

Berdasarkan tabel kriteria analisis data penilaian validasi ahli media didapatkan dengan presentase nilai akhir sebesar $85 \%$ masuk pada kriteria "Sangat Layak". Kemudian, dosen ahli media berperan untuk memberikan penilaian terhadap media dari segi kebahasaan. Dosen yang menjadi ahli bahasa yakni Ibu Yoma
Hatima, M.Pd selaku dosen mata kuliah Psikosastra pada Jurusan Pendidikan Guru Sekolah Dasar dan Ibu Ilmi Solihat, M.Pd selaku dosen mata kuliah Stilistika pada jurusan Pendidikan Bahasa dan Sastra Indonesia. Kedua dosen tersebut adalah dosen pada Universitas Sultan Ageng Tirtayasa.

Tabel 3. Data Penilaian Validasi Ahli Bahasa

\begin{tabular}{|c|c|c|c|c|}
\hline No. & $\begin{array}{c}\text { Aspek } \\
\text { Penilaian }\end{array}$ & $\begin{array}{c}\text { Ahli } \\
\text { Bahasa } \\
\text { I }\end{array}$ & $\begin{array}{c}\text { Ahli } \\
\text { Bahasa } \\
\text { II }\end{array}$ & $\begin{array}{c}\text { Skor } \\
\text { Rata- } \\
\text { rata }\end{array}$ \\
\hline $1 . \quad$ Kebahasaan & 48 & 46 & 47 \\
\hline \multicolumn{2}{|c|}{ Jumlah } & 4 & 46 & $\mathbf{4 7}$ \\
\hline \multicolumn{2}{|c|}{ Rerata Skor } & 4,8 & 4,8 & $\mathbf{4 , 7}$ \\
\hline \multicolumn{2}{|c|}{ Presentase Nilai } & $96 \%$ & $92 \%$ & $\mathbf{9 4} \%$ \\
\hline
\end{tabular}

Berdasarkan tabel kriteria analisis data penilaian validasi ahli bahasa didapatkan presentase nilai akhir sebesar $94 \%$ masuk pada kriteria "Sangat Layak". Media pembelajaran yang telah divalidasi tentu memiliki kriteria kelayakannya masing-masing, berikut peneliti akumulasi hasil validasi media oleh para ahli secara keseluruhan.

Tabel 4. Penilaian Rata-rata Validasi Para Ahli

\begin{tabular}{|c|l|c|}
\hline No. & \multicolumn{1}{|c|}{ Validator } & $\begin{array}{c}\text { Jumlah Seluruh } \\
\text { Skor (\%) }\end{array}$ \\
\hline 1. & Ahli Materi 1 & 100 \\
\hline 2. & Ahli Materi 2 & 92,2 \\
\hline 3. & Ahli Media 1 & 88,18 \\
\hline 4. & Ahli Media 2 & 81,81 \\
\hline 5. & Ahli Bahasa 1 & 96 \\
\hline 6. & Ahli Bahasa 2 & 92 \\
\hline \multicolumn{2}{c}{ Jumlah } & 550,19 \\
\hline & Rata-rata & $\mathbf{9 1 , 7 0 \%}$ \\
\hline
\end{tabular}

Media pembelajaran scrapbook ini telah melalui tiga tahap penelitian pengembangan dengan memenuhi kriteria keberhasilan. Adapun kriteria keberhasilannya berupa penilaian validasi ahli minimal dapat dinyatakan dengan kategori layak. Berdasarkan tabel penilaian ratarata validasi para ahli memperoleh nilai presentase $91,70 \%$ dan berdasarkan pedoman konversi data kuantitatif ke kualitatif maka media scrapbook masuk ke dalam kategori "Sangat Layak".

Uji coba terbatas dilakukan pada tanggal 26 dan 27 April 2018. Kelas III-A menjadi sampel dalam penelitian ini sekaligus menjadi 
tempat untuk menguji coba media scrapbook. Jumlah responden sebanyak 17 siswa.

Hasil uji coba terbatas mendapat jumlah presentasi nilai akhir yaitu diperoleh mencapai $89,83 \%$ dan berdasarkan pedoman konversi data kuantitatif ke kualitatif maka media scrapbook masuk ke dalam kategori "Sangat Baik".

Indikator keberhasilan dalam penelitian ini, yakni terselesaikaannya pengembangan media pembelajaran berbasis visual berupa scrapbook. Media pembelajaran telah selesai karena telah melalui tiga tahap penelitian pengembangan, yakni tahap define, tahap design, dan tahap develop dengan memenuhi kriteria keberhasilan. Adapun kriteria keberhasilannya, yakni penilaian validasi ahli minimal dapat dinyatakan dengan kategori layak dan berdasarkan penilaian rata-rata validasi para ahli memperoleh nilai presentase sebesar 91,70\% dan berdasarkan pedoman konversi data kuantitatif ke kualitatif maka media scrapbook masuk ke dalam kategori "Sangat Layak". Oleh sebab itu, dapat disimpulkan bahwa media scrapbook sangat layak digunakan sebagai media pembelajaran khususnya pada materi karangan deskripsi dalam mata pelajaran bahasa Indonesia di kelas III Sekolah Dasar.

Hasil pengembangan Scrapbook Petualangan Syamil dan Syifa, diharapkan dapat membantu guru dalam kegiatan belajar dan mengajar serta diharapkan dapat membantu siswa dalam memahami materi karangan sederhana (karangan deskripsi) khususnya di kelas III SD di semester II . Selain itu juga diharapkan media scrapbook dapat menambah referensi media pada materi karangan sederhana (karangan deskripsi).

Untuk itu perlu adanya pemilihan media pembelajaran yang sesuai dengan materi yang akan diajarkan, karena motivasi belajar siswa dan minat siswa dalam proses pembelajaran merupakan salah satu indikasi dari tersampaikannya informasi serta berhasilnya tujuan intruksional dalam proses pembelajaran (Sukmanasa dkk 2017: 172).

Pertimbangan lain yang diperlukan guru saat memilih media pembelajaran adalah kesesuaian media dengan tahapan perkembangan kognitif siswa. Merujuk pada teori perkembangan kognitif Jean Piaget, perkembangan kognitif (intelektual) individu berlangsung dalam 4 tahap, yakni (1) tahap sensorimotor, tahap ini berkembang dari mulai 0 - 2 tahun; (2) tahap praoperasional, mulai dari 2 7 tahun; (3) tahap operasional kongkrit, tahap ini berkembang dari $7-11$ tahun; (4) Operasi formal, yakni dimulai dari 11 tahun sampai dewasa (Nursalim 2007 : 26).

Merancang media pembelajaran bagi seorang guru ialah salah satu bagian dalam kegiatan perancangan dan pelaksanaan pembelajaran, hal itulah yang disebut kompetensi pedagogik yang dimiliki guru. Berdasarkan pasal 28 ayat 3 PP tahun 2005 tentang Standar Nasional Pendidikan dalam Nur (2014: 68) menyatakan bahwa yang dimaksud dengan kompetensi pedagogik adalah kemampuan mengelola pembelajaran peserta didik yang meliputi a. pemahaman terhadap peserta didik; $b$. perancangan dan pelaksanaan pembelajaran, evaluasi hasil belajar, dan pengembangan peserta didik untuk mengaktualisasikan berbagai potensi yang dimilikinya. Oleh karena itu, setiap guru harus senantiasa meningkatkann kompetensi pedagogik ini, salah satunya dengan mengembangkan sebuah media pembelajaran.

\section{SIMPULAN}

Penelitian ini menggunakan model 3-D yang terdiri atas tiga tahapan. Pertama, tahap define yang terdiri dari kegiatan analisis kurikulum, analisis kebutuhan, analisis materi. Kedua, tahap design yang terdiri dari mendesain media dan dilanjut pembuatan media scrapbook. Ketiga, tahap develop yang terdiri dari validasi ahli (ahli media, ahli materi, dan ahli bahasa), revisi produk, dan uji coba terbatas. Pada tahapan pembuatan scrapbook dilakukan dalam 6 tahapan yakni, pembuatan storyboard sebagai rancangan awal, pengumpulan gambar yang dibutuhkan untuk pembuatan media scrapbook petualangan Syamil dan Syifa, pengeditan gambar menggunakan aplikasi Ms. Word, mencetak gambar pada kertas $\mathrm{A} 3+$, penyusunan teknik scrapbook dan tahapan terakhir adalah penjilidan.

Tingkat validasi media scrapbook melibatkan 3 ahli materi yakni 2 guru sebagai ahli materi, 2 dosen sebagai ahli media, dan 2 dosen sebagai ahli bahasa. Tingkat validitas media dari segi materi mencapai $96,11 \%$ yang masuk dalam kategori sangat layak, tingkat validitas media dari segi media mencapai $85 \%$ yang masuk dalam kategori sangat layak, dan tingkat validitas media dari segi bahasa mencapai $94 \%$ yang masuk dalam kategori sangat layak. Berdasarkan penilaian rata-rata validasi ahli sebesar 91,70 \% dan berdasarkan pedoman konversi data kuantitatif ke kualitatif maka media scrapbook masuk ke dalam kategori 
Dewi, Tiara Kusnia., dan Yuliana, Rina

PENGEMBANGAN MEDIA PEMBELAJARAN SCRAPBOOK ...

REFLEKSI EDUKATIKA : Jurnal Ilmiah Kependidikan, Nomor 9, Volume 1, Desember 2018, hlm. 19-25

"Sangat Layak". Respon siswa terhadap media scrapbook yang dikembangkan pada tahap uji coba terbatas dan melibatkan 17 orang responden menghasilkan presentase $89,83 \%$ yang termasuk dalam kategori "Sangat Baik".

\section{DAFTAR PUSTAKA}

Abidin, Yunus. 2015. Pembelajaran Bahasa Berbasis Pendidikan Karakter. Bandung: PT Refika Aditama.

Anugraheni, Indri. 2018. Pengembangan Perangkat Pembelajaran Matematika Berbasis Pendidikan Karakter Kreatif di Sekolah Dasar. Jurnal Refleksi Edukatika, 8 (2).

Arsyad, Azhar. 2011. Media Pembelajaran. Jakarta: Raja Grafindo Persada.

Damayanti, Meita dan Ulhaq Zuhdi. 2017. Pengaruh Media Scrapbook (Buku Tempel) Terhadap Hasil Belajar Siswa Materi Keragaan Rumah Adat di Indonesia Kelas IV Sekolah Dasar. Jurnal Penelitian Pendidikan Guru Sekolah Dasar 05 (03).

Fathurohman, Irfai, dkk. 2014. Film Animasi sebagai Media Pembelajaran Terpadu untuk Memacu Keaksaraan Multibahasa Pada Siswa Sekolah Dasar. Jurnal Refleksi Edukatika 4 (1).

Heryaneu, Yekeu. Amir, Pepen. 2015. Efektivitas Penggunaan Media Scrapbook untuk Meningkatkan Kemampuan Menulis Karangan Deskripsi. Bandung: Universitas Pendidikan Indonesia. Tersedia: https://repository.upi.edu.ac.id. [05 Agustus 2017].

Hosnan, M. 2014. Pendekatan Saintifik dan Kontekstual Dalam Pembelajaran Abad 21. Bogor : Ghalia Indonesia.

Kasmaboti. 2016. Peningkatan Aktivitas dan Kemampuan Menulis Karangan Deskripsi Melalui Penggunaan Peta Konsep Pada Siswa Kelas IV SD 09 Koto Kampung
Dalam Kabupaten Padang Pariaman. Jurnal Konseling dan Pendidikan, 4 (1).

Nur, Anifa Alfia. 2014. Meningkatkan Kompetensi Pedagogik Guru di SD Yayasan Mutiara Gambut. 2 (1).

Perdanita, Ariska Dwi Wulan. 2017. Peningkatan Keterampilan Menulis Karangan Deskripsi Menggunakan Media Gambar Pada Mata Pelajaran Bahasa Indonesia. E-Jurnal Mitra Pendidikan, 1 (1).

Puspidalia, Yuantie Sova. 2012. Problematika Pembelajaran Bahasa Indonesia di MI/SD dan Alternatif Pemecahannya. Jurnal Cendekia STAIN Ponorogo, 10 (1).

Sari, Devita. 2014. Pembelajaran Menulis Teks Eksposisi Pada Siswa Kelas VII SMP XAVERIUS 3 Bandar Lampung. Jurnal Kota (Bahasa, Sastra, dam Pembelajarannya).

Sukmanasa, Elly, dkk. 2017. Pengembangan Media Pembelajaran Komik Digital Pada Mata Pelajaran Ilmu Pengetahuan Sosial Bagi Siswa Kelas V Sekolah Dasar di Kota Bogor. JPSD Untirta, 3 (2).

Sugiyono. 2010. Metode Penelitian Pendidikan Pendekatan Kuantitatif, Kualitatif, dan $R \& D$. Bandung: Alfabeta.

Sunarto. 2010. Pengembangan KreativitasInovatif dalam Pendidikan Seni melalui Pembelajaran Mukidi. Jurnal Refleksi Edukatika, 8 (2).

Triambodo, Gilang. 2015. Peningkatan Kemampuan Menulis Karangan Deskripsi Melalui Media Lingkungan dalam Pembelajaran Bahasa Indonesia. Jurnal Universitas PGRI Yogyakarta.

Trianto. 2012. Model Pembelajaran Terpadu Konsep, Strategi dan Implementasinya dalam KTSP. Jakarta: PT Bumi Aksara. 